\title{
Why Do Practitioners Want to Connect with Researchers? Evidence from a Field Experiment
}

\author{
Adam Seth Levine, Cornell University
}

ABSTRACT Researchers often want to increase the broader societal impact of their work. One way to do that is to discuss research findings directly with practitioners. Yet, such interactions are voluntary and do not regularly arise, which raises a key demand question: Under what conditions do practitioners want to connect with researchers? This article shows that relational considerations affect these decisions-that is, what practitioners expect the interaction will be like. I partnered with a US-based civic association to conduct a field experiment. I find that group leaders in this association are more likely to speak with researchers after learning that the researchers will (1) efficiently share information during the interaction, and (2) value practitioners' knowledge. The results provide actionable guidance for how researchers should approach practitioners and also demonstrate one powerful way that social science evidence can inform efforts to bridge research and practice.

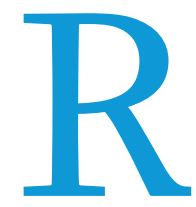

esearchers have a long-standing desire to increase the societal impact of their findings (Bowers and Testa 2019; Nyhan, Sides, and Tucker 2015; Sides 2011; Skocpol 2014). One way to do that is to directly interact with practitioners to discuss how and whether research findings are useful in a particular context. These interactions are examples of informal collaborations in which people with diverse forms of knowledge engage in a dynamic interaction that entails sharing information, being open to learning from others, and being mindful of the boundaries of what they know (Murray 1998).

From the perspective of researchers, directly interacting with practitioners in this way is beneficial for two reasons. The first is that it can produce powerful new research ideas (Green and Gerber 2010). This, in turn, can sometimes lead to more formal collaborations in which they work with practitioners on a shared project with mutual ownership and decision-making authority. The second reason is that direct interactions increase the likelihood that practitioners use research findings to inform their decision making. Scientific findings often do not speak for themselves but interactions enable a two-way flow of information that sharpens their relevance (Nutley, Walter, and Davies 2007).

Adam Seth Levine (D) is associate professor of government at Cornell University. He can be reached at ASL22@cornell.edu.

712 PS • October 2020

(C) The Author(s), 2020. Published by Cambridge University Press on behalf of

The importance of interactions, along with the fact that they typically are voluntary, raises a key demand question: Under what conditions do practitioners want to connect with researchers? Previous work suggests several factors that matter. Practitioners need to perceive that researchers offer practically useful information (Druckman 2015), including an overview of a large research literature, evidence that will help them make an immediate decision, ideas about how they can better measure their impact, and/or ideas for a new formal collaboration (Levine 2020a). They also need to perceive researchers as trustworthy-that is, as having aligned rather than competing interests (Lupia 2014).

Building on this work, I argue in this article that there is another set of factors that matter: relational considerations. To understand why, first consider that a large literature in social psychology finds that people quickly and unconsciously apply stereotypes to evaluate others. These stereotypes exist along two broad dimensions: competence and warmth (Fiske et al. 2002). In part, these dimensions capture the factors mentioned previously-the perception that the other person has relevant information (competence) and is trustworthy (warmth). Yet, in addition to trustworthiness, warmth also reflects relational considerations regarding whether the experience of interacting with the other person is enjoyable-that is, what some authors refer to as the other person's friendliness/likeability (Leary 2010; van Dijk et al. 2017). 
As applied to the context in this article, there is good reason to believe that practitioners may be uncertain about whether interacting with researchers will be an enjoyable experience. For example, a 2019 survey of Americans found that $43 \%$ agreed that research scientists "feel superior to others" (Pew Research Center
First, to my knowledge, previous work does not systematically study the formation question by comparing those who connected with those who had the opportunity to connect but chose not to. Second, and along these lines, when the argument is that both sides need to be mutually respectful, it may be unclear how to

\section{The importance of interactions, along with the fact that they typically are voluntary, raises a key demand question: Under what conditions do practitioners want to connect with researchers?}

2019). This finding echoes long-standing anti-intellectual currents in American public opinion (Cramer 2016; Gauchat 2012; Merkley 2020; Motta 2018; Zhang and Mildenberger 2020). ${ }^{1}$ For instance, Hofstadter $(1966,273,275)$ noted that "applied science would have been immensely useful to farmers" in the nineteenth century, yet there was great "resentment" toward interacting with those who advocated using scientific methods to improve farming. Hofstadter (1966) also observed that many outside of the scientific community raised concerns about whether scientists are interested in efficiently communicating what they know with those who are busy and whose immediate goal is practical decision making. These examples echo interviews with nonprofit practitioners that I conducted in 2017 to better understand their hesitation about engaging with researchers (see the online supplementary material for more details). Two of the specific reasons why they thought that the experience might not be enjoyable reflected concerns about (1) whether researchers would be interested in hearing about what they know, and (2) how much researchers would respect their time constraints by efficiently sharing only the most practice-oriented information. explicitly put that into practice. Doing so requires operationalizing what it means to be mutually respectful in a given context. Third, this article also makes a methodological contribution because, to my knowledge, this is the first field experiment to study the conditions under which new relationships between researchers and practitioners arise.

\section{FIELD EXPERIMENT TESTING THE IMPORTANCE OF RELATIONAL FACTORS}

For this experiment, I partnered with a national civic association based in the United States. This organization raises public awareness of one of the most pressing issues of our time: climate change. It is based in Washington, DC, but has a chapter structure that includes at least one chapter in almost every congressional district across the country. Federated civic associations like this one have long been important for increasing awareness and advocating for new solutions in the public sphere (Han 2014). Having a strong group of committed volunteers in each chapter is central to this work.

Each chapter has one or more leaders. The organization conducts an annual survey of these group leaders; in recent years,

\section{...there is good reason to believe that practitioners may be uncertain about whether interacting with researchers will be an enjoyable experience.}

Taken together, recent and historical work suggests that practitioners may not automatically perceive that connecting with researchers will be an enjoyable experience, especially for two main reasons. Based on these considerations, I hypothesized that they will be more interested in connecting when they believe that the scientists will (1) value practitioners' knowledge, and (2) efficiently share what they know. ${ }^{2}$ To test these hypotheses, I conducted a field experiment in which a large group of practitioners was given the opportunity to speak with a scientist about research related to their goals. I found that their desire to connect increases after receiving information that the scientist would be engaging in either of these two ways.

This finding contributes to a growing evidence base across the social sciences on how to connect researchers and practitioners, including in education (Penuel and Gallagher 2017), management (Bartunek 2007), public health (Cargo and Mercer 2008), and public understanding of science (Brossard and Lewenstein 2009). These other scholars suggest that relational considerations are vital by noting the importance of mutual respect. Yet, several questions remain unresolved, which this study aims to address. they (1) frequently report wanting more new ideas for how to mobilize and organize volunteers, and (2) lament the fact that they are incredibly busy and do not feel that they have much time to devote to this goal. These findings suggested that leaders would gain value from connecting with a researcher who could provide a bespoke overview of findings on political participation and social movements that pertain to volunteer commitment, as well as from a discussion about how to put those ideas into practice.

\section{Experimental Procedure}

The study took place in January 2019. My organizational partner provided the list of 828 group leaders across the country. From that list, I randomly chose one leader from each chapter. If a chapter had only one leader, I chose that person; otherwise, I randomly chose one. This produced a sample of $45^{6}$ group leaders, who then were randomly assigned to receive one of four emails (described in the next subsection) inviting them to have a conversation with a social scientist. 
They had one week to respond, at which point they were matched with a researcher. ${ }^{3}$ This article focuses only on the formation stage (i.e., the take-up rate). That said, it is worth noting the broader significance of what transpired. Group leaders who responded engaged in a one-on-one conversation in which they and a researcher worked together to define the issue vis-à-vis the local community. They discussed how existing research on volunteer commitment could be useful in their local context. In some cases, there were follow-up conversations as well. Group leaders experienced direct impact via substantial increases in volunteer commitment and action taking (Levine 2019). The researcher, meanwhile, gained vital first-hand knowledge about challenges associated with implementation-that is, the reason why group leaders "knowing what to do" is distinct from "feeling comfortable doing it."

\section{Treatments}

Group leaders were randomly assigned to receive one of four invitations. The control group received a baseline message that emphasized the content of what they would learn: they were being offered the opportunity to have a conversation with a researcher about new work related to boosting volunteer commitment. The message was sent and signed by a member of the climate organization's national staff, which boosted credibility by signaling her belief that the researcher would be trustworthy and share practically useful information. Figure 1 depicts the baseline email message (with several redactions to avoid identifying information).

We chose to present the opportunity as the climate organization partnering with a matchmaking organization that would do the actual matchmaking. Although having a second organizational partner (i.e., this matchmaking organization in addition to the climate organization) was not strictly necessary, we believed it further enhanced the credibility of the message and was therefore worthwhile.

The other three messages included one extra paragraph in the middle, immediately before the paragraph that starts with "Interested?" These paragraphs were similar in format-they each referenced the experiences of other practitioners who had been matched by the matchmaking organization in the past. Two of the paragraphs stated different ways in which the experience was enjoyable, thereby testing my key hypotheses (i.e., "efficiently share what they know" and "value others' expertise"). The third paragraph included extra information about what those previous practitioners had learned (i.e., "more details about shared information"). This third version rules out an alternative hypothesis that simply providing any extra information on participants' previous experiences affects take-up rates. The "efficiently share what they know" paragraph read as follows:

Previous participants reported that it was an extremely efficient experience. The researchers acknowledged that folks are busy and don't have time to keep up on all the latest research they might wish to. So, the name of the game is efficiency-they provide a concentrated dose of "news you can use."

The "value others' expertise" paragraph read as follows:

Previous participants reported that it was an extremely pleasant and affirming experience. They said that the researchers they spoke with were kind, respectful, genuinely interested in their work, and very clearly wanted to learn about their organizations.

The "more details about information shared" paragraph read as follows:

Previous participants reported that it was an extremely informative experience. The researchers shared a wide variety of new techniques for providing emotional support to volunteers (such as using legitimation rhetoric, memory heuristics, and selfdisclosure). They also shared many techniques for deepening volunteers' commitment to a cause (such as new ways of eliciting commitments, providing reasons, and citing social proof).

\section{RESULTS}

The outcome measure is the take-up rate (Levine 2020b). Figure 2 graphically summarizes all four groups. Overall, 10.5\% (i.e., 48 of

\title{
Figure 1 \\ Email Invitation in Control Group
}

\author{
Hello [Group Leader],
}

We wanted to start off the new year with an exciting opportunity for our group leaders!

Want to strengthen your volunteer base as we gear up to [build awareness of climate change and one possible response to it]?

If so, you're in luck! We're partnering with [matchmaking organization], allowing any interested group leader to talk to an expert about the latest techniques for volunteer engagement, and how you can apply them in your chapter.

[Matchmaking organization] connects organizations with social scientists eager to share research on how to recruit new volunteers and further engage existing ones. They've already connected over 40 volunteers and staff with researchers from across the country.

Interested? Just send a quick note to [email address] by this [date] if you wish to take part.

Include your name, email address, and a one-line note saying you're interested. Then [individual associated with matchmaking organization] will respond to schedule a 30 minute phone conversation at a time that's convenient for you

Your participation in this opportunity can help [climate organization name] improve its training and operations as we gear up for supporting our volunteers throughout the country in this critical year ahead.

Thank you for all you do,

[Director of volunteer engagement for climate organization] 


\section{Figure 2}

\section{Behavior in Field Experiment, by Experimental Condition (Including +/- $1 \mathrm{SE}$ )}

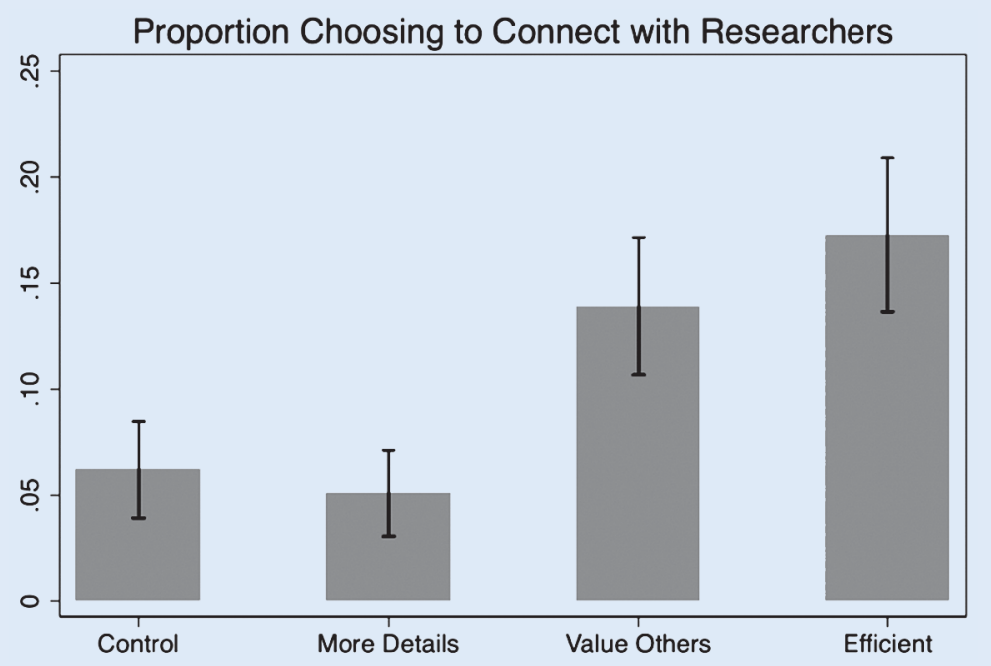

Note: There were 113 people in the control group, 118 in the "more details" group, 115 in the "value others" group, and 110 in the "efficient" group.

456 group leaders) chose to connect; $6.2 \%$ of those who received the baseline message did so (i.e., seven people) compared with $17.3 \%$ (i.e., 19 people) who received the "efficiently share what they know" message and $13.9 \%$ who received the "value others' expertise" message (i.e., 16 people). In addition, only $5.1 \%$ of respondents (i.e., six people) chose to connect after receiving "more details" about the content of what they would discuss.

The difference-in-proportions test that compared the control group and "value others' expertise" is significant $(p=0.05$; all tests are two-tailed), as is the test that compared the control group with those who received the "efficiently share what they know" message $(p=0.01)$. I also found that the average take-up rates in the "value others' expertise" and "efficiently share what they know" groups are statistically indistinguishable $(p=0.49)$. This provides evidence in support of the broader theoretical point that what matters is communicating that the experience will be enjoyable, and that these are two ways to effectively do so in this context. ${ }^{4}$ Finally, I did not find evidence that providing more details increased the take-up rate relative to the control group $(p=0.71) .^{5}$ One possible reason is that, although this information was germane, it included terms that may have been more difficult to process. When presented with a description of a novel behavior, people use "ease of processing" as a heuristic for the ease of engaging in that behavior. In this case, it may have suppressed demand even though the information was goal relevant (Song and Schwarz 2008).

Table 1 presents two logistic regressions. Model 1 includes only dummy variables for the three treatment groups. Model 2 also controls for three pretreatment variables that were available based on data supplied by my partner organization: sex of group leader (male or female) and location, from which I could infer the political party of their congressional delegation (i.e., a key cleavage of climate politics in the United States). ${ }^{6}$ The results in model 1 mirror those mentioned previously: practitioners are far more likely to choose to connect when they receive information that researchers will efficiently share what they know or that they will value their expertise. A Wald test indicates that the two coefficients representing this addition of relational language are statistically indistinguishable $(p=0.49)$. Moreover, again, I do not have evidence that these patterns were simply the result of providing additional information about others' previous experiences; information about details to be discussed did not significantly affect behavior. These results are robust to the inclusion of the three

Table 1

\section{Demand to Connect with Researchers}

\begin{tabular}{lll} 
& Model 1 & Model 2 \\
\hline "More Details" Condition & -0.21 & -0.29 \\
\hline "Value Others" Condition & $(0.57)$ & $(0.58)$ \\
\hline & $0.89^{*}$ & $0.85^{*}$ \\
\hline "Efficient" Condition & $(0.47)$ & $(0.48)$ \\
\hline & $1.15^{* * *}$ & $1.13^{* *}$ \\
\hline \# of Republican Senators & $(0.46)$ & $(0.47)$ \\
\hline & & 0.32 \\
\hline Republican Representative & & $(0.20)$ \\
\hline & & -0.57 \\
\hline Female & & $(0.36)$ \\
\hline Constant & & $0.57^{*}$ \\
\hline & $-2.72^{* * *}$ & $(0.32)$ \\
\hline InL & $(0.39)$ & $-3.03^{* * *}$ \\
\hline$\chi^{2}$ & -146.98 & -143.12 \\
\hline$N$ & 12.93 & 18.83 \\
\hline
\end{tabular}

Notes: Table entry is the logit coefficient with standard error below. Dependent Variable: Decision to connect with researcher, $\mathrm{O}(\mathrm{No})$ or 1 (Yes). ${ }^{*} p<0.10$; ${ }^{* *} p<0.05$; ${ }^{* * *} p<0.01$, two-tailed $z$-tests. 
pretreatment variables (see model 2 in table 1), in which I also found evidence that female group leaders were more interested in connecting than male group leaders.

\section{CONCLUSION AND FUTURE WORK}

Relational considerations matter when people with diverse forms of knowledge have the opportunity to interact with one another. This study shows how this insight can explain when practitioners choose to connect with researchers. Researchers who want to initiate new connections with practitioners can benefit from explicitly conveying (1) how they will efficiently share what they know, and (2) that they are interested in and value the expertise of the practitioners with whom they want to speak. accelerate the societal impact of political science as well as other social science research.

\section{ACKNOWLEDGMENTS}

I greatly appreciate the opportunity to collaborate with my partner organization. For feedback and intellectual inspiration, I also owe many thanks to Jake Bowers, Dominique Brossard, Dan Butler, Bryce Corrigan, Don Green, Bruce Lewenstein, Heather Marquette, Melissa Sands, and Neil Stenhouse. I also thank the Rita Allen Foundation for generous funding that made this project possible.

\section{Researchers who want to initiate new connections with practitioners can benefit from explicitly conveying (1) how they will efficiently share what they know, and (2) that they are interested in and value the expertise of the practitioners with whom they want to speak.}

As in any individual experiment, the degree to which these results generalize requires further research. For instance, my partner organization held generally favorable attitudes toward science and the value of using science to further its mission (evidenced by the decision to partner with me on this project). Yet, even here, relational concerns were a barrier. However, what would happen in situations in which there might be greater hostility toward academic knowledge and/or academics more generally (c.f. Hofstadter 1966, 273-75)?

To explore these and other critical questions, the theoretical foundation in this article provides a useful starting point, along with other premises that are relevant when connecting people with diverse forms of knowledge (e.g., researchers and practitioners). The first premise is that they often begin as strangers, and strangers often are hesitant to interact with one another (Epley and Schroeder 2014). The second premise is that status-based stereotypes impact how people value the knowledge that others bring to the table and, in turn, how people perceive the relevance of their own knowledge (Ridgeway 2001). The third premise is that organizational capacity and the opportunity to engage in new connections are distributed unevenly. These three premises provide a useful starting point for investigating other factors that influence (1) the formation and impact of new connections, and (2) how institutions can facilitate them. For instance, whereas this article focuses on a key aspect of how community leaders perceive researchers, future work should study researchers' perceptions of leaders and other practitioners, and which interventions may affect their desire to connect. Future work also should further investigate the precise ways in which these connections affect (or do not affect) decision making. Finally, the desire to build new relationships, and the outcome of having done so, also may be studied through interviews and surveys in which it is easier to measure individual-level attributes (e.g., ideology, anti-intellectual attitudes, experiences, and stereotypes) that may impact both formation and impact.

Overall, this article underscores the need and opportunity to build new connections between researchers and practitioners. An expanded evidence base on how to build them will greatly

\section{DATA AVAILABILITY STATEMENT}

Replication materials can be found on Dataverse at: https://doi. org/10.7910/DVN/B3Y1GZ

\section{SUPPLEMENTARY MATERIALS}

To view supplementary material for this article, please visit http:// dx.doi.org/10.1017/S1049096520000840. -

\section{NOTES}

1. Whereas there are growing ideological differences in trust in the scientific enterprise, even as recently as 2010 , only $50 \%$ of liberals expressed "a great deal" of confidence in the scientific community (Gauchat 2012).

2. For purposes of this article, I use the terms "scientist" and "researcher" interchangeably.

3. To streamline the process (and because of my personal knowledge of the relevant research), all respondents were matched with me.

4. For more on the importance of comparing across treatments, see Gelman and Stern (2006). In addition, I can reject the null hypothesis of no difference in the following cases: comparing "more details" and "value others' experience" $(p=0.02)$ and comparing "more details" and "efficiently share what they know" ( $p=0.003)$.

5. Results are robust to randomization inference (see online supplementary material).

6. The online supplementary material includes more details regarding these pretreatment covariates.

\section{REFERENCES}

Bartunek, Jean M. 2007. “Academic-Practitioner Collaboration Need Not Require Joint or Relevant Research: Toward a Relational Scholarship of Integration." Academy of Management Journal 5o (6): 1323-33.

Bowers, Jake, and Paul Testa. 2019. "Better Government, Better Science: The Promise of and Challenges Facing the Evidence-Informed Policy Movement." Annual Review of Political Science 22:28.1-28.22.

Brossard, Dominique, and Bruce V. Lewenstein. 2009. "A Critical Appraisal of Models of Public Understanding of Science: Using Practice to Inform Theory." In Communicating Science: New Agendas in Communication, ed. LeeAnn Kahlor and Patricia Stout, 11-39. New York: Routledge.

Cargo, Margaret, and Shawna L. Mercer. 2008. "The Value and Challenges of Participatory Research: Strengthening Its Practice." Annual Review of Public Health 29:325-50.

Cramer, Katherine J. 2016. The Politics of Resentment: Rural Consciousness in Wisconsin and the Rise of Scott Walker. Chicago: University of Chicago Press. 
Druckman, James N. 2015. "Communicating Policy-Relevant Science.” PS: Political Science \& Politics 48 (S1): 58-69.

Epley, Nicholas, and Juliana Schroeder. 2014. "Mistakenly Seeking Solitude." Journal of Experimental Psychology General 143 (5):1980-99.

Fiske, Susan T., Amy J. C. Cuddy, Peter Glick, and Jun Xu. 2002. "A Model of (Often Mixed) Stereotype Content: Competence and Warmth Respectively Follow from Perceived Status and Competition." Journal of Personality and Social Psychology 82 (6): 878-902.

Gauchat, Gordon. 2012. "Politicization of Science in the Public Sphere: A Study of Public Trust in the United States, 1974 to 2010." American Sociological Review 77 (2): $167-87$.

Gelman, Andrew, and Hal Stern. 2006. "The Difference Between "Significant" and "Not Significant" Is Not Itself Statistically Significant." The American Statistician $60(4): 328-31$.

Green, Donald P., and Alan S. Gerber. 2010. "Introduction to Social Pressure and Voting: New Experimental Evidence.” Political Behavior 32 (3): 331-36.

Han, Hahrie. 2014. How Organizations Develop Activists. Oxford, UK: Oxford University Press.

Hofstadter, Richard. 1966. Anti-Intellectualism in American Life. New York: Alfred A. Knopf.

Leary, Mark R. 2010. "Affiliation, Acceptance, and Belonging: The Pursuit of Interpersonal Connection." In Handbook of Social Psychology, Vol. 2, ed. Susan T. Fiske, Daniel T. Gilbert, and Gardner Lindzey, 864-97. Hoboken, NJ: John Wiley \& Sons, Inc.

Levine, Adam Seth. 2019. "Why Social Science? Because It Tells Us How to Create More Engaged Citizens.” Available at www.whysocialscience.com/ blog/2019/9/24/because-it-tells-us-how-to-create-more-engaged-citizens.

Levine, Adam Seth. 2020a. "Research Impact Through Matchmaking (RITM): Why and How to Connect Researchers and Practitioners." PS: Political Science E Politics 53 (2): 265-69.

Levine, Adam Seth. 202ob. "Replication Data for: Why Do Practitioners Want to Connect with Researchers? Evidence from a Field Experiment." Available at Harvard Dataverse, doi:10.7910/DVN/B331GZ.

Lupia, Arthur. 2014. "What Is the Value of Social Science?" PS: Political Science $\mathcal{E}$ Politics 47 (1): 1-7.
Merkley, Eric. 2020. "Anti-Intellectualism, Populism, and Motivated Resistance to Expert Consensus.” Public Opinion Quarterly. Available at DOI:10.31219/osf.io/ qkd57.

Motta, Matthew. 2018. "The Polarizing Effect of the March for Science on Attitudes toward Scientists." PS: Political Science \& Politics 51 (4): 782-88.

Murray, Vic. 1998. "Interorganizational Collaborations in the Nonprofit Sector." In International Encyclopedia of Public Policy and Administration, Vol. 2, ed. J. M. Shafirtz, 1192-96. Boulder, CO: Westview.

Nutley, Sandra M., Isabel Walter, and Huw T. O. Davies. 2007. Using Evidence: How Research Can Inform Public Services. Bristol, UK: The Policy Press.

Nyhan, Brendan, John Sides, and Joshua Tucker. 2015. "APSA as Amplifier: How to Encourage and Promote Public Voices within Political Science.” PS: Political Science \& Politics 48 ( $\left.\mathrm{S}_{1}\right)$ : 90-93.

Penuel, William R., and Daniel J. Gallagher. 2017. Creating Research-Practice Partnerships in Education. Cambridge, MA: Harvard Education Press.

Pew Research Center. 2019. "Most Americans Have Positive Image of Research Scientists, but Fewer See Them as Good Communicators." Available at www.pewresearch.org/fact-tank/2019/08/19/most-americans-have-positiveimage-of-research-scientists-but-fewer-see-them-as-good-communicators. Accessed August 20, 2019.

Ridgeway, Cecilia L. 2001. "Social Status and Group Structure." In Blackwell Handbook of Social Psychology: Group Processes, ed. Michael A. Hogg and R. Scott Tindale, 352-75. Hoboken, NJ: John Wiley \& Sons, Inc.

Sides, John. 2011. "The Political Scientist as a Blogger." PS: Political Science \& Politics 44 (2): $267-71$.

Skocpol, Theda. 2014. "How the Scholars Strategy Network Helps Academics Gain Public Influence." Perspectives on Politics 12 (3): 695-703.

Song, Hyunjin, and Norbert Schwarz. 2008. "If It's Hard to Read, It's Hard to Do: Processing Fluency Affects Effort Prediction and Motivation." Psychological Science. 19 (10): 986-88.

Van Dijk, Hans, Bertolt Meyer, Marloes van Engen, and Denise Lewin Loyd. 2017. "Microdynamics in Diverse Teams: A Review and Integration of the Diversity and Stereotyping Literatures." Academy of Management Annals 11 (1): 517-57.

Zhang, Baobao, and Matto Mildenberger. 2020. "Scientists' Political Behaviors Are Not Driven by Individual-Level Government Benefits." PLOS One, May 6. 